Itinéraires Itinéraires

Littérature, textes, cultures

2009-3 | 2009

Modernités occidentales et extra-occidentales

\title{
Dilip Parameshwar Gaonkar (dir.), Alternative Modernities
}

\section{Cyril Vettorato}

\section{(2) OpenEdition}

1 Journals

Édition électronique

URL : http://journals.openedition.org/itineraires/556

DOI : 10.4000/itineraires.556

ISSN : 2427-920X

Éditeur

Pléiade

\section{Édition imprimée}

Date de publication : 1 novembre 2009

Pagination : 180-182

ISBN : 978-2-296-10115-9

ISSN : 2100-1340

\section{Référence électronique}

Cyril Vettorato, « Dilip Parameshwar Gaonkar (dir.), Alternative Modernities », Itinéraires [En ligne], 2009-3 | 2009, mis en ligne le 26 juin 2014, consulté le 22 septembre 2020. URL : http:// journals.openedition.org/itineraires/556 ; DOI : https://doi.org/10.4000/itineraires.556

\section{cc) (1)}

Itinéraires est mis à disposition selon les termes de la licence Creative Commons Attribution - Pas d'Utilisation Commerciale - Pas de Modification 4.0 International. 
la question des rapports entre le groupe et l'individu au sein de la petite revue (d'une manière générale, et à travers l'exemple de Coterie). Un aspect particulièrement important de la revue moderniste est son goût pour les dialogues entre pays et entre disciplines : deux articles portent ainsi sur deux «passeurs » de culture essentiels dans l'univers moderniste, Philippe Soupault et T. S. Eliot, qui chacun de son côté s'efforce de créer un pont entre Europe et Amérique; un autre montre à quel point le monde de la science a pu influencer les créations littéraires modernistes. Enfin, le rôle crucial de l'art et de l'image dans l'élaboration du modernisme donne lieu à quatre articles portant sur divers aspects de la question : l'art abstrait dans la revue Plastique, le rôle de BLAST et de Jacob Epstein, l'importance de la photographie à travers le Camera Works de Stieglitz, l'évolution de l'avant-garde parisienne telle qu'on la perçoit dans la petite revue française L'Élan.

\section{Valérie Sourisseau \\ Université Paris $13-$ CENEL}

Dilip Parameshwar Gaonkar (dir.), Alternative Modernities, Durham et Londres, Duke University Press, 2001.

D'abord publié en tant que numéro de la revue Public Culture cofondée par Arjun Appadurai, Alternative Modernities rassemble des études d'une grande diversité disciplinaire, sous la direction de Dilip Parameshwar Gaonkar. C'est ce dernier qui, dans un article ayant presque valeur de manifeste, tente de faire exister ces textes ensemble autour d'un projet commun, celui d'illustrer l'existence de « modernités alternatives ». S'opposant à une vision monolithique de la modernité, ce concept vise à nous doter d'outils intellectuels pour penser la diversité des incarnations du moderne dans des sites excentrés par rapport au noyau occidental. Parler de modernités alternatives revient dès lors à reconnaître que la modernité est partout et que, née dans un contexte sociohistorique précis, elle s'est peu à peu étendue au monde entier sans pour autant résulter en son uniformisation.

Gaonkar débute sa réflexion par un retour sur la modernité occidentale ellemême, dont il met en valeur le récit dominant. Ce récit se fonde sur une distinction entre la modernisation sociétale, cette transformation sociale et cognitive du monde qui correspond à l'émergence de l'ordre bourgeois, et la modernité culturelle qui s'y oppose, rejetant le conformisme bourgeois au profit d'une valorisation du sujet, des expériences authentiques et de l'expression spontanée. Pratiquement tous les récits de la modernité occidentale ont pris pour point de départ un tel dilemme, qui recouvre une division entre des aspects jugés positifs et d'autres vus comme négatifs. Ce récit d'une modernité à deux faces ne peut être adopté pour évoquer d'autres théâtres de la modernité. La perspective des modernités alternatives invite ainsi à une renarration du moderne : l'idée notamment selon laquelle la modernisation sociétale mènerait inéluctablement vers un certain mode d'organisation quel que soit le site affecté est fausse, tout comme celle qui 
voudrait que la culture moderne prenne forcément la forme d'un art privilégiant l'expression de la subjectivité.

Cette renarration opère un basculement d'une théorie aculturelle de la modernité, dans laquelle la transition vers le moderne constitue un ensemble d'opérations sans dimension culturelle, à une théorie culturelle de la modernité, qui accepte le fait que la modernité occidentale soit elle-même une culture. Dans cette perspective, la modernité se déploie toujours dans un contexte civilisationnel spécifique, produisant des résultats variables en fonction de ce dernier. Le concept fondamental de cette théorie culturelle est celui d'adaptation créative : on désigne par là la façon dont les peuples vont à la rencontre de la modernité, se l'approprient de façon active. Ce concept nous amène naturellement à mettre en valeur les moyens à travers lesquels les personnes se rendent elles-mêmes modernes, plutôt que d'être rendues modernes par une force extérieure. En somme, il désigne la façon dont les gens questionnent leur présent, ce qui est la définition même de la modernité.

Dans son article « Two theories of modernity », Charles Taylor approfondit cette distinction entre théorie culturelle et théorie aculturelle de la modernité, montrant que la seconde domine à tort nos représentations depuis le $\mathrm{XIX}^{\mathrm{e}}$ siècle. Plutôt que de voir la modernité comme une opération neutre qui pourrait se déployer au sein de n'importe quel site, il conviendrait de désigner par ce terme le monde atlantique contemporain vu comme une culture, avec sa propre compréhension de ce que sont une personne, la nature et le bien. Nous avons trop pensé la modernité comme une perte - de fausses croyances, de mythes trompeurs - sans voir qu'elle était portée par sa propre vision spirituelle. Une telle erreur implique ce que Taylor nomme un « ethnocentrisme du présent », dans lequel l'état moderne des choses est pensé comme culturellement neutre. De plus, la lecture aculturelle nous interdit de percevoir les adaptations créatives, car elle se fonde sur l'idée selon laquelle le monde moderne tout entier est appelé à converger. La théorie culturelle permet au contraire de valoriser la multiplicité des transformations culturelles qui constituent les modernités alternatives.

De nombreuses illustrations de ces transformations complexes sont apportées par les études de cas menées dans le volume. Dans son article, l'historien Dipesh Chakrabarty examine la pratique de l'adda à Calcutta dans la première moitié du $\mathrm{XX}^{\mathrm{e}}$ siècle. Il s'agit là de longues discussions légères et informelles entre amis, perçues comme profondément liées à l'identité bengalaise. À l'époque moderne, l'adda a constitué un moyen de se sentir chez soi dans le capitalisme moderne, de l'habiter activement. Le rapport de l'adda aux valeurs modernes est pourtant très ambivalent : cette pratique est tout à la fois porteuse de telles valeurs (discours démocratique, cosmopolitanisme littéraire) et promeut un ethos contraire aux valeurs bourgeoises (éthique du travail, domesticité bourgeoise) en excluant les femmes et en invitant à négliger travail et responsabilités civiles. Un autre exemple d'adaptation créative est offert par l'article de Tejaswini Nirajana, où sont évoquées les femmes d'origine indienne de Trinidad. Un discours et des pratiques de l' « indianité » se sont développés dans la nation caraïbe, s'opposant à l'identité africaine dominante. Une forme de musique en particulier, le soca, mélange de calypso et de musique indienne, est apparue, mettant en scène des femmes indiennes chantant des sujets épicés : ce produit culturel 
contemporain témoigne de l'adaptation à une situation nationale particulière à caractère biracial. L'article de Michael Hanchard «Afro-modernity » examine pour sa part l'existence d'une modernité spécifique aux personnes d'origine africaine. Bien que dépourvu d'une langue ou même d'un territoire propre, le discours panafricain moderne a su se développer, inventant une « communauté imaginée », pour reprendre l'expression de Benedict Anderson. Cet effort adaptatif a permis de nourrir une lutte contre ce que Hanchard nomme le «temps racial », c'est-à-dire les inégalités de temporalité résultant des relations de pouvoir entre dominants et dominés - accès temporel inégal aux institutions, biens, services, ressources, pouvoirs et savoirs.

Malgré cette forte prégnance du transnational dans le volume, l'échelle de la nation est souvent privilégiée pour rendre les modernités et leurs effets plus lisibles. Dans un essai philosophique ayant pour titre « On reconciling cosmopolitan unity and national diversity », Thomas McCarthy pose la question du cosmopolitanisme. Existe-t-il une forme de nationalisme compatible avec ce dernier? Le propre du capitalisme est d'engendrer un besoin de supranationaliser les lois et la politique. Dans ce contexte, les théoriciens du politique se sont trouvés face à la nécessité de concevoir la structure de base d'un système de justice cosmopolitique, afin de protéger les droits individuels. McCarthy prend pour point de départ la solution kantienne d'une " république mondiale » composée de républiques nationales souveraines, avant d'en montrer les limites pour la dépasser à l'aide du modèle d'Habermas. Celui-ci met à jour la proposition kantienne en y intégrant l'idée démocratique, en mettant en avant le respect de la multiplicité des formes de vie ainsi que l'impératif égalitariste. McCarthy conclut sa discussion en mobilisant la pensée de Charles Taylor sur les « modernités alternatives ». Taylor résiste à l'idée d'unification des cultures : si la globalisation engendre une nécessité de trouver des normes de coexistence au-delà des frontières culturelles, il ne doit pas forcément se produire de transformations culturelles uniformisantes. Dans l'optique de l'établissement d'un système de lois transnational, il distingue les normes d'actions et leurs justifications. Il n'est possible d'attendre de convergence entre les nations que sur le plan des normes d'actions, suite à une discussion plurielle qui viserait à un consensus transnational ; les justifications à ces normes, en revanche, varieraient selon la culture considérée.

Dans l'essai d'Elizabeth Povinelli, la nation moderne australienne est confrontée à son « autre » intérieur, le peuple aborigène; l'auteur explore les ambiguïtés voire l'impossibilité des lois de réparation visant à résoudre une tension affectant le projet national. Dans son article, Andrew Wachtel met en relation l'identité nationale russe avec la pratique de la traduction, montrant comment le projet culturel soviétique s'est inscrit dans le projet de traduction universelle qui avait été ressenti comme la mission de la Russie au XIX ${ }^{\mathrm{e}}$ siècle. Plusieurs autres sites sont examinés (le Mexique, la Chine, le Brésil) afin de mettre en relation l'invention de projets nationaux et la modernité, montrant comment la confrontation au moderne ne peut produire que des actualisations multiples et spécifiques au site examiné. 